\title{
Estudo da Carcaça e da Carne de Bubalinos Mediterrâneo Terminados em Confinamento com Diferentes Fontes de Volumoso
}

\author{
Fabiano Nunes Vaz ${ }^{1}$, João Restle ${ }^{2}$, Ivan Luiz Brondani ${ }^{3}$, Paulo Santana Pacheco ${ }^{4}$
}

\begin{abstract}
RESUMO - O objetivo deste trabalho foi estudar as características de carcaça e da carne de bubalinos Mediterrâneo terminados em confinamento por 112 dias e alimentados com dietas isoprotéicas (12\% de proteína bruta) contendo, na matéria seca, 33\% de concentrado e $67 \%$ de cana-de-açúcar ou silagem de milho. Foram utilizados doze novilhos bubalinos, com idade de 20 meses. O peso de fazenda, peso de carcaça quente e peso de carcaça fria foram similares entre os tratamentos, sendo, respectivamente, 363,7; 181,8; e 179,9 kg, para os animais alimentados com cana-de-açúcar, e 361,3; 186,8; e 184,2 kg, citados na mesma ordem, para os bubalinos alimentados com silagem de milho, sendo que estes apresentaram maior rendimento de carcaça fria que os animais alimentados com cana-de-açúcar (51,7 contra 49,9\%). Não houve diferença na porcentagem dos cortes comerciais da carcaça, assim como nas medidas de desenvolvimento da carcaça entre os animais dos dois tratamentos. O tratamento não afetou a conformação de carcaça, área de longissimus dorsi, assim como as porcentagens de músculo e osso na carcaça, sendo que, na média dos dois tratamentos, essas características apresentaram valores de 9,0 pontos; $52,1 \mathrm{~cm}{ }^{2}, 62,8$ e $16,5 \%$. Na média, os bubalinos apresentaram porcentagem de gordura de 20,8\% e 2,96 mm de espessura de gordura subcutânea. Não houve diferença significativa nas características cor, textura, marmoreio, força de cizalhamento, maciez e quebra na cocção da carne, mas a quebra ao descongelamento foi maior e a palatabilidade e suculência da carne, superiores nos animais alimentados com cana-de-açúcar.
\end{abstract}

Palavras-chave: cana-de-açúcar, carcaça de bubalinos, carne de bubalinos, silagem de milho, qualidade da carne

\section{Study of Carcass and Meat of Mediterranean Buffalos Finished in Feedlot with Different Roughage Sources}

\footnotetext{
ABSTRACT - The objective of this work was to study the carcass and meat characteristics of Mediterranean buffalos, finished in feedlot for 112 days and fed with $33 \%$ concentrate and $67 \%$ chopped sugar cane or corn silage diets, containing $12 \%$ of crude protein. Twelve buffalos steers, with 20 months of age, were used. Slaughter weight, hot carcass weight and cold carcass weight were similar between the treatments, being, respectively, 363.7, 181.8 and $179.9 \mathrm{~kg}$, for animals fed with chopped sugar cane, and 361.3, 186.8 and $184.2 \mathrm{~kg}$, in the same order, for buffalos fed with corn silage. Buffalos fed with corn silage showed higher cold dressing percentage than the animals fed with chopped sugar cane (51.7 vs. 49.9\%). No difference was observed for carcass commercial cuts percentage, as well as for carcass development measures between the animals of the two treatments. Treatment did not affect carcass conformation, longissimus dorsiarea, as well as carcass muscle and bone percentages, being the averages of the two treatments, for these characteristics, respectively, 9.0 points, $52.1 \mathrm{~cm}^{2}, 62.8$ and $16.5 \%$. The buffalos showed an average carcass fat percentage of $20.8 \%$ and $2.96 \mathrm{~mm}$ of subcutaneous fat thickness. No significant difference was observed for meat color, texture, marbling, Shear value, tenderness and cooking loss, but the thawing loss was higher, and the flavor and juiciness were superior for animals fed with chopped sugar cane.

Key Words: buffalos carcass, buffalos meat, corn silage, meat quality, chopped sugar cane

\section{Introdução}

Deve-se fomentar a bubalinocultura de corte, a qual já tem conquistado espaço na pecuária de corte brasileira, principalmente em função da rusticidade dos animais, bastante adaptados a solos de baixa fertilidade e terrenos alagadiços, onde algumas raças bovinas não apresentam a mesma produtividade (Charles \& Johnson, 1975; Muller et al., 1991).

Além disso, Joksimovic (1969) relata que, em razão da sua qualidade, a carne bubalina pode substituir a carne bovina, até com algumas vantagens, principalmente em razão da menor quantidade de gordura que apresenta.

Estudando a terminação de bubalinos e bovinos, Mazza et al. (1984) utilizaram, em confinamento, capim-elefante e cana-de-açúcar $+10 \%$ de concentrado (na MS), observando que, embora sendo mais

${ }^{1}$ Zootecnista, Bolsista do CNPq, Aluno do curso de Doutorado CEPAN - UFRGS. Rua Benjamin Constant, 930/313, Santa Maria - RS, CEP 97050-020. E.mail: fnvaz@terra.com.br

2 Eng.-Agr., PhD, Pesquisador do CNPq, Professor Titular do Departamento de Zootecnia - UFSM, Santa Maria - RS, CEP 97105-900. E.mail: jorestle@ccr.ufsm.br

3 Zootecnista, Dr., Professor Adjunto do Departamento de Zootecnia - UFSM, Santa Maria - RS, CEP 97105-900.

${ }^{4}$ Aluno do curso de Mestrado em Zootecnia - UFSM.
} 
jovens ao abate, os bubalinos apresentaram maior peso de carcaça resfriada que os bovinos $(209,0$ contra $176,5 \mathrm{~kg}$ ), não diferindo no rendimento de carcaça, mesmo que tenham apresentado maior peso relativo de cabeça (2,55 contra $2,31 \%$ ) e de couro (11,73 contra $8,76 \%)$ em relação ao peso de abate. Os mesmos autores sugerem que os bubalinos foram economicamente mais eficientes que os bovinos, devido aos maiores rendimentos quantitativos de cortes dianteiro, costilhar e serrote.

Os bubalinos apresentaram maior peso de abate, quando comparados com bovinos Nelore ou Aberdeen Angus, porém mostraram maior percentual de ossos na carcaça que os bovinos das raças Charolês, Aberdeen Angus e Nelore e menor rendimento de carcaça que os novilhos Nelore (Moletta \& Restle, 1996a). Ao estudarem as características qualitativas da carcaça e da carne, Moletta \& Restle (1996b) chegaram à conclusão de que os bubalinos apresentam carne que necessita menor força de cizalhamento que a de bovinos Nelore e, embora tenham mostrado maior perda durante à cocção, não apresentaram diferença na suculência e palatabilidade.

Por outro lado, grande parte dos conceitos validados para a carne bovina pode ser aplicada para a carne de bubalinos (Joksimovic, 1969; Robertson et al., 1986). Portanto, para que essa carne conquiste espaço na mesa dos consumidores, a mesma deve ser proveniente do abate de animais jovens, pois, segundo Vaz \& Restle (1998), um dos principais fatores que restringem o consumo de carne bovina no Brasil é o fato de que a mesma não possui qualidade constante, já que a carne oferecida nos mercados pode ser proveniente de animais jovens ou reprodutores descartados dos rebanhos de corte e leiteiro, em função da idade avançada.

Em seu trabalho, Restle (1999) relata que a melhoria de qualidade da carne bovina passa pela correta utilização das tecnologias disponíveis ao produtor brasileiro, podendo-se citar os sistemas alimentares, que devem ser priorizados, por reduzirem a idade ao abate e, dessa forma, a carne produzida apresenta boa qualidade, caracterizada, principalmente, por boa maciez, coloração e textura (Berg \& Butterfield, 1976; Boggs \& Merkel, 1981; Di Marco, 1994). Entre os sistemas alimentares que reduzem a idade ao abate dos animais, o confinamento deve ser considerado. Franzolin \& Silva (2001) concluem, em seu trabalho, que os bubalinos possuem bom potencial de produção de carcaça com bons rendimentos de cortes comerciais, quando terminados em regime de confinamento.
Vários trabalhos discutem os níveis e a qualidade dos concentrado utilizados nos confinamentos de bovinos (Vaz et al., 2000), porém, quando se trata de bubalinos, que são animais de maior rusticidade e com maior capacidade de digerir fibras de pior qualidade (Charles \& Johnson, 1975), o volumoso torna-se de grande importância, pois no confinamento de bubalinos pode participar em maior proporção da dieta, sem afetar o desempenho dos mesmos (Restle \& Vaz, 1999; Martinez, 2000). Franzolin \& Silva (2001) estudaram diferentes níveis energéticos na dieta de bubalinos confinados, verificando que o nível alimentar da dieta não alterou o rendimento de carcaça quente, que foi de 50,88; 51,37; e 51,57\%, respectivamente, para os níveis baixa energia, energia requerida e alta energia.

O objetivo deste trabalho foi estudar o efeito do uso de silagem de milho ou cana-de-açúcar na terminação de bubalinos da raça Mediterrâneo em confinamento, sobre as características quantitativas e qualitativas da carcaça e da carne, bem como estabelecer as correlações entre essas variáveis.

\section{Material e Métodos}

Este experimento foi conduzido nas dependências do Setor de Bovinocultura de Corte do Departamento de Zootecnia da Universidade Federal de Santa Maria, situada na Depressão Central do Rio Grande do Sul, a uma altitude de $95 \mathrm{~m}$, latitude de $29^{\circ} 43^{\prime}$ sul e longitude $53^{\circ} 42^{\prime}$ oeste.

Foram terminados em confinamento 12 bubalinos da raça Mediterrâneo, com idade de 20 meses, contemporâneos, oriundos do mesmo rebanho, sendo sempre mantidos sob as mesmas condições de manejo, alimentação e sanidade. Em confinamento, os animais permaneceram por quatro períodos de 28 dias, sendo que a relação volumoso : concentrado (base da MS), do primeiro ao quarto período experimental foi de $78: 22,76: 24,61: 39$ e 56:44, respectivamente. O concentrado foi composto por farelo de arroz, grão de milho, farelo de soja, calcário, sal e farinha de ossos e, como volumoso, metade dos animais recebeu silagem de milho e outra metade, cana-de-açúcar. O concentrado foi o mesmo para os dois tratamentos; os animais que consumiram cana-de-açúcar receberam uréia misturada diretamente no cocho, no momento do fornecimento, visando manter a dieta dos dois tratamentos com $12 \%$ de proteína bruta. A composição das dietas experimentais está apresentada na Tabela 1. 
Os bubalinos, quando atingiram, na média de todos os animais, aproximadamente $3 \mathrm{~mm}$ de gordura de cobertura (considerado pelos frigoríficos como acabamento adequado para o abate), foram todos comercializados (na mesma data), sendo submetidos, antes do embarque para o frigorífico, a um jejum de sólidos de 12 horas e, posteriormente, pesados, obtendo-se, dessa maneira, o peso de fazenda dos animais.

$\mathrm{O}$ abate ocorreu conforme o fluxo normal do matadouro. Após o abate, a remoção do couro e evisceração dos animais, as carcaças foram identificadas, lavadas e resfriadas a $-2^{\circ} \mathrm{C}$ por 24 horas. Decorrido esse tempo, as carcaças foram novamente pesadas, realizando-se a avaliação da conformação e maturidade fisiológica das carcaças, conforme as escalas e metodologia sugeridas por Muller (1987).

As carcaças também foram medidas para obter-se o comprimento de carcaça, de perna e de braço, além do perímetro de braço e da espessura de coxão. Após

Tabela 1 - Composição da dieta, de acordo com o período experimental

Table 1 - Diet composition according to the experimental period

\begin{tabular}{lcccc}
\hline Característica & \multicolumn{4}{c}{$\begin{array}{c}\text { Período experimental } \\
\text { Experimental period }\end{array}$} \\
\cline { 2 - 5 } & 1 & 2 & 3 & 4 \\
\hline $\begin{array}{l}\text { Concentrado } \\
\text { Concentrate }\end{array}$ & 22,000 & 24,000 & 39,000 & 44,000 \\
$\begin{array}{l}\text { Farelo de arroz } \\
\text { Rice meal }\end{array}$ & 5,729 & 7,030 & 11,575 & 13,424 \\
$\begin{array}{l}\text { Grão de milho } \\
\text { Corn grain }\end{array}$ & 1,692 & 2,578 & 13,268 & 16,540 \\
$\begin{array}{l}\text { Farelo de soja } \\
\text { Soybean meal }\end{array}$ & 13,246 & 12,948 & 11,856 & 11,449 \\
$\begin{array}{l}\text { Farinha de ossos } \\
\text { Bone meal }\end{array}$ & 0,458 & 0,499 & 0,776 & 0,871 \\
$\begin{array}{l}\text { Calcário calcítico } \\
\text { Limestone } \\
\text { Sal comum }\end{array}$ & 0,667 & 0,715 & 1,143 & 1,276 \\
$\begin{array}{l}\text { Salt } \\
\begin{array}{l}\text { Volumoso } \\
\text { Roughage }\end{array}\end{array}$ & 0,209 & 0,230 & 0,382 & 0,440 \\
$\begin{array}{l}\text { Uréia* } \\
\text { Urea* }\end{array}$ & 78,000 & 76,000 & 61,000 & 56,000 \\
\hline
\end{tabular}

* Somente oferecida aos animais alimentados com cana-deaçúcar.

* Only offered to the animals fed diet with chopped sugar cane. essas medidas, foi realizado um corte perpendicular no músculo longissimus dorsi, na altura da $12^{\mathrm{a}}$ costela, onde foram avaliadas as características cor, textura e marmoreio de carne e medidas a área de longissimus dorsi e a espessura de gordura sobre o mesmo.

Para determinar a porcentagem dos cortes comerciais, dividiu-se a meia-carcaça direita em dianteiro, traseiro e costilhar e, por intermédio de pesagem, calculou-se a porcentagem destes em relação à meiacarcaça. A determinação da composição física da carcaça foi feita pela extração de uma amostra localizada entre a 9 ${ }^{a}$ e $11^{a}$ costela da meia-carcaça direita (Hankins \& Howe, 1946). Essa amostra foi dessecada, por meio da separação física de músculo, gordura e osso, conforme os procedimentos sugeridos por Muller (1987). A porção do músculo longissimus dorsi, extraída dessa peça, foi embalada, identificada e congelada. Após o congelamento, foram extraídas, de cada amostra, duas fatias (fatias A e B) de $2,5 \mathrm{~cm}$, obtidas perpendicularmente ao comprimento do músculo.

Para cálculo das perdas ao descongelamento e cocção, foi realizada a pesagem da fatia $\mathrm{B}$, ainda congelada, depois de descongelada (antes de ser levada ao forno) e após o cozimento, que aconteceu até que a temperatura interna da fatia atingisse $70^{\circ} \mathrm{C}$. A pesagem após o cozimento foi realizada após a fatia voltar à temperatura ambiente. Após cozimento e pesagem da fatia, foram extraídas três amostras de feixes de fibras, circulares, com $1 \mathrm{~cm}^{2}$ de área, as quais foram cortadas perpendicularmente à fibra, por intermédio do aparelho Warner-Bratzler Shear, que mede a resistência das fibras ao corte.

A fatia $A$ foi descongelada e cozida juntamente com a fatia B; após a cocção, foi distribuída, da fatia A, uma porção de $2 \times 2 \mathrm{~cm}$ para cada um dos quatro avaliadores, os quais foram previamente treinados para atribuírem valores de 1 a 9 para as características maciez, suculência e palatabilidade da carne.

$\mathrm{O}$ delineamento experimental foi o inteiramente casualizado, com dois tratamentos e seis repetições. Os dados foram submetidos à análise de variância e teste $\mathrm{F}$, em nível de $10 \%$, por intermédio do programa estatístico SAS (1990). O mesmo programa realizou o estudo de correlação entre as variáveis dependentes por intermédio do cálculo dos coeficientes de correlação de Pearson. 


\section{Resultados e Discussão}

Os dados referentes às características de peso ao abate, peso de carcaça, rendimento e quebra durante o resfriamento da carcaça, conforme o volumoso oferecido, são apresentados na Tabela 2. Observa-se que o peso final não foi influenciado ( $\mathrm{P}>0,8151)$ pela fonte de volumoso utilizada, sendo de 363,7 e $361,3 \mathrm{~kg}$, respectivamente, para cana-deaçúcar e silagem de milho. Estudando o desempenho de bubalinos terminados em confinamento, pastagem cultivada ou campo nativo, Costa et al. (1994) observaram peso de abate de 442, 467 e $469 \mathrm{~kg}$, respectivamente. Macedo et al. (2000) estudaram as características de carcaça de bubalinos Mediterrâneo terminados com diferentes sistemas alimentares, observando que não houve diferença entre os tratamentos no peso de abate dos animais.

Franzolin \& Silva (2001) variaram o nível de energia na dieta de bubalinos Mediterrâneo alimentados em confinamento, observando que o peso de abate foi similar entre os níveis de energia, $20 \%$ abaixo da energia requerida para bubalinos em crescimento ( $0,8 \mathrm{~kg}$ de ganho diário) e $20 \%$ acima do nível requerido para crescimento $(0,8 \mathrm{~kg}$ de ganho diário), sendo as médias de 462,4 e 473,6 kg, respectivamente, para os níveis baixo e alto.

Os pesos de carcaça quente e de carcaça fria também não diferiram significativamente entre os dois tratamentos analisados (Tabela 2); a quebra no resfriamento foi de 1,08 e $1,45 \%$, respectivamente, para animais alimentados com cana-de-açúcar e silagem de milho ( $\mathrm{P}>0,5109)$. Trabalhando com três sistemas alimentares diferentes, Muller et al. (1994b) observaram maior quebra ao resfriamento $(2,87 \%)$ nos bubalinos mantidos em pastagem nativa que nos mantidos em pastagem cultivada (2,00\%). Em sua pesquisa, Franzolin \& Silva (2001) observaram que as quebras durante o resfriamento da carcaça foram similares entre três níveis de energia utilizados na dieta.

Moletta et al. (1993a) avaliaram bubalinos pastejando duas gramíneas, Brachiaria humidicula e Hemarthria altissima, verificando que os animais que consumiram $B$. humidicula como volumoso apresentaram maior peso de carcaça quente $(218,87 \mathrm{~kg})$ que os bubalinos que consumiram H. altissima $(208,62 \mathrm{~kg})$, e m razão do maior rendimento de carcaça apresentado pelos primeiros $(51,22$ contra $48,83 \%)$, já que os animais não mostraram diferença no peso de abate, que foi de 434,16 e 420,00 kg, respectivamente. No presente trabalho, observa-se (Tabela 2) que os animais alimentados com silagem de milho como volumoso mostraram maior rendimento de carcaça fria que os bubalinos que consumiram cana-de-açúcar.

Costa et al. (1994) concluíram que bubalinos terminados em pastagem cultivada apresentaram rendimento de carcaça de $50,9 \%$, enquanto nos animais mantidos em pastagem nativa o rendimento foi de 49,4\%. Muller et al. (1994b) verificaram maior rendimento de carcaça $(52,98 \%)$ em bubalinos mantidos em pastagem cultivada que naqueles terminados em campo nativo $(50,17 \%)$. Comparando

Tabela 2 - Médias e erros-padrão (EP) para peso de fazenda, pesos de carcaça quente e fria, quebra no resfriamento e rendimento de carcaça fria de bubalinos Mediterrâneo alimentados com duas fontes de volumoso

Table 2 - Means and standard errors (EP) for slaughter weight, hot and cold carcass weight, chilling loss and dressing percentage of Mediterranean buffalos fed diets with two roughage sources

\begin{tabular}{|c|c|c|c|c|}
\hline \multirow[t]{2}{*}{$\begin{array}{l}\text { Característica } \\
\text { Characteristic }\end{array}$} & \multicolumn{2}{|c|}{$\begin{array}{c}\text { Fonte de volumoso } \\
\text { Roughage source }\end{array}$} & \multirow[t]{2}{*}{$\mathrm{EP}$} & \multirow[t]{2}{*}{$\begin{array}{l}\text { Probabilidade } \\
\text { Probability }\end{array}$} \\
\hline & $\begin{array}{c}\text { Cana-de-açúcar } \\
\text { Chopped sugar cane }\end{array}$ & $\begin{array}{l}\text { Silagem de milho } \\
\text { Corn silage }\end{array}$ & & \\
\hline Peso de fazenda, $\mathrm{kg}$ & 363,7 & 361,3 & 6,9 & 0,8151 \\
\hline $\begin{array}{l}\text { Slaughter weight, } \mathrm{kg} \\
\text { Peso de carcaça quente, } \mathrm{kg} \\
\text { Hot carcass weight, } \mathrm{kg}\end{array}$ & 181,8 & 186,8 & 4,8 & 0,4819 \\
\hline $\begin{array}{l}\text { Peso de carcaça fria, } \mathrm{kg} \\
\text { Cold carcass weight, } \mathrm{kg}\end{array}$ & 179,9 & 184,2 & 4,9 & 0,5525 \\
\hline $\begin{array}{l}\text { Quebra no resfriamento, } \% \\
\text { Chilling loss, } \%\end{array}$ & 1,08 & 1,45 & 0,38 & 0,5109 \\
\hline $\begin{array}{l}\text { Rendimento de carcaça fria, \% } \\
\text { Dressing percentage, } \%\end{array}$ & 49,9 & 51,7 & 0,7 & 0,0998 \\
\hline
\end{tabular}


bubalinos e bovinos, Jorge et al. (1997) concluíram que os últimos apresentam rendimento de carcaça superior, em decorrência do menor peso relativo de cabeça e couro.

Segundo Vaz et al. (2001), o principal fator responsável pelas diferenças no rendimento de carcaça em bovinos é o conteúdo e desenvolvimento do trato digestório. Esses autores prosseguem, afirmando que os animais que necessitam consumir mais alimentos para suprir suas exigências fisiológicas, ou consomem alimentos com taxa de passagem mais lenta pelo trato digestório, desenvolvem mais o rúmen-retículo, resultando em animais com maior peso do trato digestório cheio e vazio, assim como maior quantidade de couro para envolver maior arqueamento de costelas. Se esses conceitos puderem ser aplicados também para bubalinos, admite-se que a cana-de-açúcar possuiu menor taxa de passagem pelo trato gastrointestinal, já que o consumo de matéria seca diário foi inferior nos bubalinos alimentados com cana-de-açúcar (Restle et al., 1994). Também comparando silagem de milho e cana-de-açúcar na terminação de novilhos em confinamento, Brondani \& Restle (1991) observaram maior consumo de matéria seca nos animais que consumiram silagem $(9,97$ contra $9,67 \mathrm{~kg})$, resultando em maior ganho de peso (1,46 contra $1,12 \mathrm{~kg})$.

Devido à adaptabilidade dos bubalinos em consumirem forragem de pior qualidade, existe maior desenvolvimento do trato digestório dos mesmos (Muller et al., 1991). Em confinamento, Rodrigues et al. (2000) afirmam que os bubalinos apresentam maior consumo de alimentos diário (2,69\% do peso vivo) que os bovinos (2,39\% do peso vivo), resultando em maior peso de abate em relação aos bovinos (380,9 contra $365,5 \mathrm{~kg}$ ).

Outros fatores relacionados ao rendimento de carcaça, em animais pertencentes ao mesmo rebanho, contemporâneos e da mesma raça, seriam aqueles ligados à deposição de gordura subcutânea e porcentagem de gordura na carcaça (Preston \& Willis, 1974). Entretanto, os animais do presente trabalho foram similares nessas características, conforme será discutido a seguir; na Tabela 3, apresentam-se os resultados referentes à espessura de gordura, composição física, conformação, área de longissimus dorsi e maturidade fisiológica da carcaça. Observa-se que os animais alimentados com silagem de milho apresentaram $3,00 \mathrm{~mm}$ de espessura de gordura e aqueles que consumiram cana-de-açúcar mostraram 2,92 mm, sendo a diferença

Tabela 3 - Médias e erros-padrão (EP) para espessura de gordura de cobertura, composição física da carcaça, conformação, área de longissimus dorsi e maturidade fisiológica da carcaça de bubalinos Mediterrâneo alimentados com duas fontes de volumoso

Table 3 - Means and standard errors (EP) for subcutaneous at thickness, physical carcass composition, conformation, longissimus dorsi area and carcass physiological maturity of Mediterranean buffalos fed diet with two roughage sources

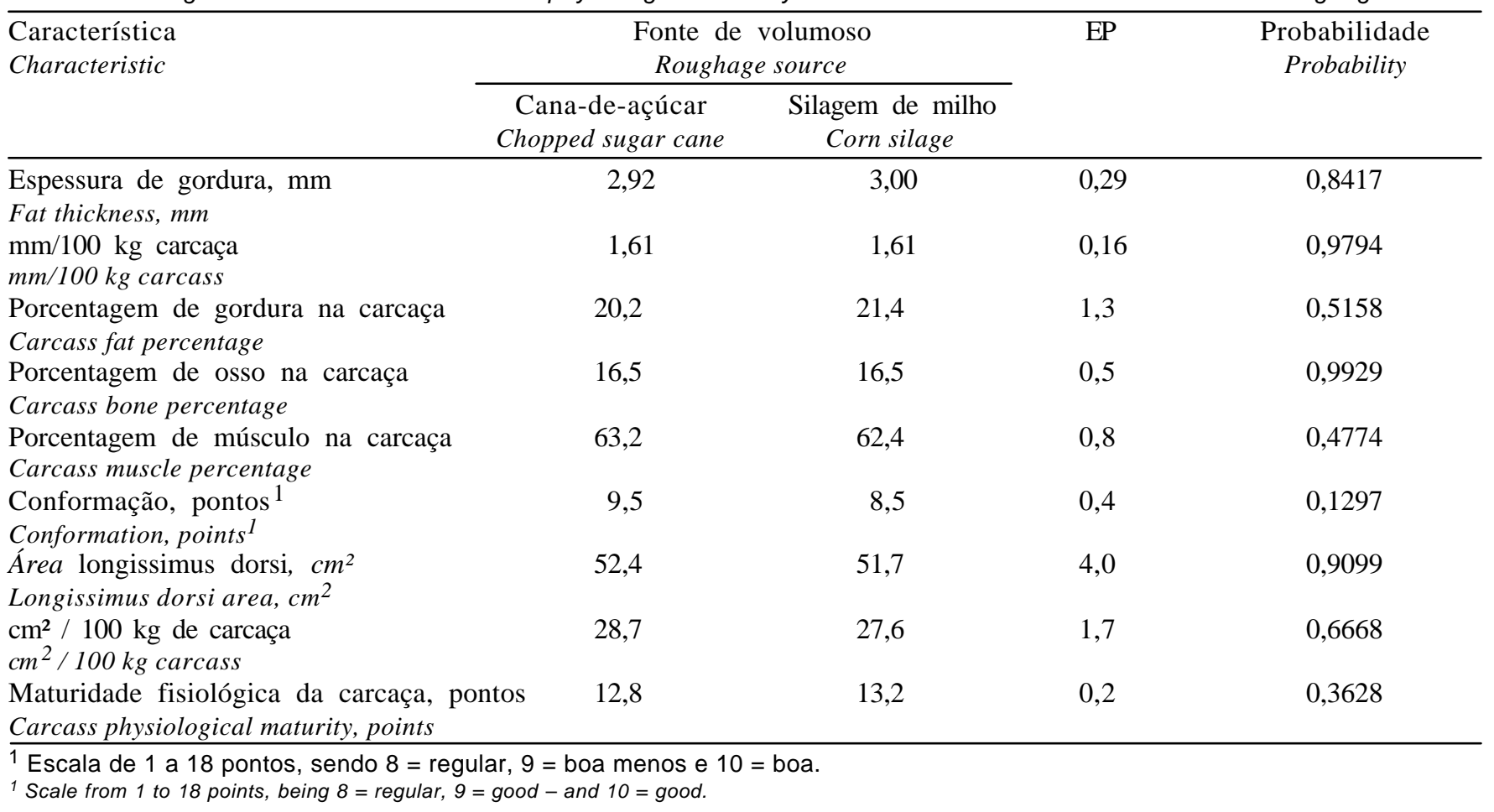


não-significativa. Ao ajustar a cobertura de gordura ao peso de carcaça dos animais, observa-se, na Tabela 3, que o valor foi o mesmo para os dois tratamentos pesquisados $(1,61 \mathrm{~mm} / 100 \mathrm{~kg}$ de carcaça fria).

A porcentagem de gordura foi de 20,2 e 21,4\%, respectivamente, para os tratamentos cana-de-açúcar e silagem de milho ( $\mathrm{P}>0,5158)$, já a porcentagem de músculo na carcaça foi de 63,2 e 62,4\% (P>0,4774), citados na mesma ordem, sendo que a porcentagem de ossos foi de 16,5\% nos dois tratamentos ( $\mathrm{P}>0,9929)$. Pesquisando o uso de diferentes sistemas alimentares na terminação de bubalinos, Muller et al. (1994a) observaram porcentagem de músculo de 58,28; 60,24; e 59,86\% (média de 59,46\%), porcentagem de gordura de 22,$32 ; 19,26$; e $21,10 \%$ (média de 20,89\%) e porcentagem de ossos de 18,$48 ; 19,25$; e $18,24 \%$ (média de 18,66\%), respectivamente, para animais mantidos em pastagem cultivada, duas horas em pastagem cultivada e restante em campo nativo e animais mantidos somente em campo nativo. Gigli et al. (1994) estudaram bubalinos alimentados com rações com dois níveis energéticos, chegando à conclusão de que o maior nível energético aumentou o total de gordura na carcaça, assim como a gordura intermuscular e subcutânea.

A conformação foi similar entre os tratamentos $(P>0,1297)$, sendo classificada entre "regular" e "re- gular mais" ( 8,5 pontos) nos animais que consumiram silagem de milho e entre "regular mais" e "boa menos" (9,5 pontos) naqueles terminados com canade-açúcar. Após a terminação de bubalinos Mediterrâneo, Muller et al. (1994a) observaram similaridade na conformação de carcaça entre os animais alimentados em diferentes sistemas de alimentação, sendo a conformação de 9,$0 ; 8,5$ e 8,5 pontos, respectivamente, para animais terminados em pastagem cultivada, animais que pastejaram somente em campo nativo e animais que pastejaram duas horas em pastagem cultivada e o restante do tempo permaneceram em campo nativo.

Lorenzoni et al. (1986) citam que bubalinos apresentam carcaças de pior conformação que bovinos, relato confirmado ao se observarem os resultados do presente trabalho, pois a média dos dois tratamentos foi de 9,0 pontos, ou seja, carcaças classificadas como "regular mais" e abaixo da classificação observada para bovinos dessa idade terminados em confinamento (Moletta \& Restle, 1996a; Vaz \& Restle, 1998).

A área de longissimus dorsi foi semelhante entre os tratamentos, tanto no valor absoluto, como no valor ajustado para o peso de carcaça. Moletta et al. (1993b) observaram, em bubalinos da raça Mediterrâneo, $65,39 \mathrm{~cm}^{2}$ de área delongissimus dorsi, valor que passou para $30,34 \mathrm{~cm}^{2}$, quando foi ajustado para

Tabela 4 - Médias e erros-padrão (EP) para percentagem dos cortes comerciais e medidas de desenvolvimento da carcaça de bubalinos Mediterrâneo alimentados com duas fontes de volumoso

Table 4 - Means and standard errors (EP) for commercial cuts percentages and carcass development measures of Mediterranean buffalos fed diet with two roughage sources

\begin{tabular}{|c|c|c|c|c|}
\hline \multirow[t]{2}{*}{$\begin{array}{l}\text { Característica } \\
\text { Characteristic }\end{array}$} & \multicolumn{2}{|c|}{$\begin{array}{c}\text { Fonte de volumoso } \\
\text { Roughage source }\end{array}$} & \multirow[t]{2}{*}{$\mathrm{EP}$} & \multirow[t]{2}{*}{$\begin{array}{c}\text { Probabilidade } \\
\text { Probability }\end{array}$} \\
\hline & $\begin{array}{c}\text { Cana-de-açúcar } \\
\text { Chopped sugar cane }\end{array}$ & $\begin{array}{l}\text { Silagem de milho } \\
\text { Corn silage }\end{array}$ & & \\
\hline Porcentagem de dianteiro & 37,2 & 36,8 & 0,3 & 0,3532 \\
\hline $\begin{array}{l}\text { Forequarter percentage } \\
\text { Porcentagem de costilhar } \\
\text { Sidecut percentage }\end{array}$ & 12,7 & 13,0 & 0,3 & 0,5131 \\
\hline $\begin{array}{l}\text { Porcentagem de serrote } \\
\text { Sawcut percentage }\end{array}$ & 50,1 & 50,2 & 0,4 & 0,8759 \\
\hline $\begin{array}{l}\text { Comprimento de carcaça, } \mathrm{cm} \\
\text { Carcass length, } \mathrm{cm}\end{array}$ & 114,8 & 113,5 & 0,8 & 0,3037 \\
\hline $\begin{array}{l}\text { Comprimento de perna, cm } \\
\text { Leg length }\end{array}$ & 63,5 & 63,5 & 0,5 & 1,0000 \\
\hline $\begin{array}{l}\text { Espessura de coxão, cm } \\
\text { Cushion thickness }\end{array}$ & 21,4 & 20,8 & 0,4 & 0,3371 \\
\hline $\begin{array}{l}\text { Perímetro de braço, } \mathrm{cm} \\
\text { Arm perimeter, } \mathrm{cm}\end{array}$ & 31,5 & 31,9 & 0,5 & 0,5714 \\
\hline $\begin{array}{l}\text { Comprimento de braço, } \mathrm{cm} \\
\text { Arm length, } \mathrm{cm}\end{array}$ & 38,9 & 38,2 & 0,4 & 0,2345 \\
\hline
\end{tabular}


$100 \mathrm{~kg}$ de carcaça. $\mathrm{O}$ fato de os animais consumirem silagem de milho ou cana-de-açúcar não afetou a maturidade fisiológica ( $\mathrm{P}>0,3628)$, conforme pode ser verificado na Tabela 3 .

$\mathrm{Na}$ Tabela 4, encontram-se os resultados referentes às porcentagens dos cortes comerciais da carcaça dos bubalinos. Nos animais alimentados com cana-de-açúcar foram observados valores de 37,2; 12,7 e $50,1 \%$, respectivamente, para porcentagem de dianteiro, de costilhar e de serrote, enquanto os animais alimentados com silagem de milho mostraram valores de 36,$8 ; 13,0$; e 50,2\%, citados na mesma ordem, sendo que nenhuma dessas características diferiu entre os tratamentos. Franzolin \& Silva (2001) pesquisaram diferentes níveis energéticos na dieta de bubalinos em confinamento, observando similaridade nas porcentagens de dianteiro e costilhar da carcaça, que, na média, foram de 38,44 e $14,12 \%$, respectivamente.
Constam ainda na Tabela 4 os resultados referentes às medidas de desenvolvimento da carcaça. $\mathrm{O}$ comprimento de carcaça foi de 114,8 e $113,5 \mathrm{~cm}$, respectivamente, para animais terminados com canade-açúcar e silagem de milho ( $\mathrm{P}>0,3037)$. Muller et al. (1994a) verificaram que o comprimento de carcaça foi o mesmo para bubalinos terminados em três diferentes sistemas alimentares, fato observado também para o comprimento de perna e de braço. No presente trabalho, também não foi verificada diferença significativa para comprimento dos membros entre os animais terminados com cana-de-açúcar e silagem de milho.

Os bubalinos dos dois tratamentos não diferiram no perímetro de braço ( $\mathrm{P}>0,5714)$ e espessura de coxão $(\mathrm{P}>0,3371)$, sendo que esta última apresentou média de $21,1 \mathrm{~cm}$ entre os dois tratamentos, valor inferior aos 25,58 cm verificados por Moletta et al.

Tabela 5 - Médias e erros-padrão (EP) para cor, textura, marmoreio, força de cizalhamento, características sensoriais e quebras durante o descongelamento e cocção da carne de bubalinos Mediterrâneo alimentados com duas fontes de volumoso

Table 5 - Means and standard errors (EP) for meat color, texture, marbling, Shear force, sensorial characteristics, thawing and cooking losses of Mediterranean buffalos fed diet with two roughage sources

\begin{tabular}{|c|c|c|c|c|}
\hline \multirow[t]{2}{*}{$\begin{array}{l}\text { Característica } \\
\text { Characteristic }\end{array}$} & \multicolumn{2}{|c|}{$\begin{array}{l}\text { Fonte de volumoso } \\
\text { Roughage source }\end{array}$} & \multirow[t]{2}{*}{$\mathrm{EP}$} & \multirow[t]{2}{*}{$\begin{array}{l}\text { Probabilidade } \\
\text { Probability }\end{array}$} \\
\hline & $\begin{array}{c}\text { Cana-de-açúcar } \\
\text { Chopped sugar cane }\end{array}$ & $\begin{array}{l}\text { Silagem de milho } \\
\text { Corn silage }\end{array}$ & & \\
\hline $\begin{array}{l}\text { Cor, pontos }{ }^{1} \\
\text { Meat color, points } 1\end{array}$ & 4,00 & 4,00 & 0,18 & 1,0000 \\
\hline $\begin{array}{l}\text { Textura, pontos } \\
\text { Meat texture, points }\end{array}$ & 3,50 & 3,67 & 0,22 & 0,5995 \\
\hline $\begin{array}{l}\text { Marmoreio, pontos } 3 \\
\text { Marbling, points }{ }^{3}\end{array}$ & 3,67 & 2,67 & 0,46 & 0,1548 \\
\hline $\begin{array}{l}\text { Força de cizalhamento, } \mathrm{kg} \\
\text { Shear force, } \mathrm{kg}\end{array}$ & 5,56 & 5,06 & 0,44 & 0,4449 \\
\hline $\begin{array}{l}\text { Maciez, pontos } 4 \\
\text { Tenderness, points }\end{array}$ & 6,50 & 6,54 & 0,30 & 0,9248 \\
\hline $\begin{array}{l}\text { Palatabilidade, pontos } 4 \\
\text { Flavor, points } 4\end{array}$ & 5,13 & 4,63 & 0,17 & 0,0612 \\
\hline $\begin{array}{l}\text { Suculência, pontos } 4 \\
\text { Juiciness, points } 4\end{array}$ & 5,25 & 4,46 & 0,27 & 0,0663 \\
\hline $\begin{array}{l}\text { Quebra no descongelamento, \% } \\
\text { Thawing loss, } \%\end{array}$ & 5,83 & 4,80 & 0,39 & 0,0908 \\
\hline $\begin{array}{l}\text { Quebra na cocção, \% } \\
\text { Cooking loss, \% }\end{array}$ & 34,0 & 35,3 & 0,8 & 0,2841 \\
\hline $\begin{array}{l}1 \text { Escala de } 1 \text { a } 5 \text { pontos, sendo } 1= \\
2 \text { Escala de } 1 \text { a } 5 \text { pontos, sendo } 1= \\
3 \text { Escala de } 1 \text { a } 18 \text { pontos, sendo } 2 \\
4 \text { Escala de } 1 \text { a } 9 \text { pontos, sendo } 1=\text { ex } \\
\text { ou extremamente suculenta. } \\
1 \text { Scale from } 1 \text { to } 5 \text { points, being } 1=\text { dark } \\
2 \text { Scale from } 1 \text { to } 5 \text { points, being } 1=\text { very } \\
3 \text { Scale from } 1 \text { to } 18 \text { points, being } 2=\text { tra } \\
4 \text { Scale from } 1 \text { to } 9 \text { points, being } 1=\text { extr }\end{array}$ & $\begin{array}{l}\text { ermelho escuro e } 5= \\
\text { nuito grosseira e } 5=\mathrm{m} \\
\text { traços, } 3=\text { traços mai } \\
\text { emamente dura, sem sc } \\
\text { ed and } 5=\text { bright red. } \\
\text { coarse and } 5=\text { very fine. } \\
\text { es, } 3=\text { traces }+ \text { and } 4=\text { s } \\
\text { mly tough, undesirable flav }\end{array}$ & $\begin{array}{l}\text { rmelho brilhante. } \\
\text { to fina. } \\
4=\text { leve menos. } \\
\text { or ou seca, } 5=\text { médio }\end{array}$ & emam & tremamente saborosa \\
\hline
\end{tabular}


(1993b) e aos 23,26 cm observados por Muller et al. (1994a), sendo ambos os trabalhos também realizados com animais da raça Mediterrâneo.

$\mathrm{Na}$ Tabela 5 são apresentadas as médias para as características cor, textura e marmoreio da carne. Observa-se que os bubalinos alimentados com canade-açúcar a carne apresentaram coloração classificada como "vermelha clara", textura entre "média" e "fina", e marmoreio "leve menos". Já nos animais que consumiram silagem de milho, essas classificações foram, respectivamente, "vermelha clara", "fina" e "traços mais", sendo que as três características não apresentaram diferença significativa entre os tratamentos. Traçando comentários sobre a carne de bubalinos, Joksimovic (1969) relata que é esperada uma coloração mais escura na carne de bubalinos, quando estes apresentarem carcaças mais magras, fatores que podem ser corrigidos por intermédio de nutrição e genética.

Constam também na Tabela 5 os resultados referentes à força de cizalhamento necessária para romper as fibras da carne, observando-se que os tratamentos foram similares, apresentando média de $5,31 \mathrm{~kg}$ para essa característica. Com relação às características sensoriais (Tabela 5), verifica-se que a maciez foi classificada como "acima da média" e "macia", respectivamente, para cana-de-açúcar e silagem de milho. Já a palatabilidade foi melhor nos animais que receberam cana-de-açúcar $(\mathrm{P}<0,0612)$. A suculência da carne também foi melhor $(\mathrm{P}<0,0663)$ nos animais que receberam cana-de-açúcar na dieta (classificada como "média") em relação aos animais que consumiram silagem de milho (classificada como "levemente abaixo da média").

A quebra durante o descongelamento da carne foi menor $(\mathrm{P}<, 0908)$ nos animais que consumiram silagem de milho $(4,80 \%)$ em comparação àqueles alimentados com cana-de-açúcar $(5,83 \%)$. Já a perda durante a cocção da carne foi similar entre os tratamentos, sendo, na média, de 34,6\%. Muller (1987) afirma que a quebra durante o descongelamento é afetada pelo marmoreio da carne. Restle et al. (1998) compararam dois volumosos na alimentação de novilhos, observando similaridade nas quebras ao descongelamento e à cocção da carne, entre os tratamentos.

$\mathrm{Na}$ Tabela 6, verificam-se as correlações entre as variáveis analisadas. Observa-se que a correlação foi significativa entre rendimento e peso de carcaça $(\mathrm{r}=0,76 ; \mathrm{P}<0,01)$. A correlação entre essas duas variáveis é comentada por Preston \& Willis (1974),

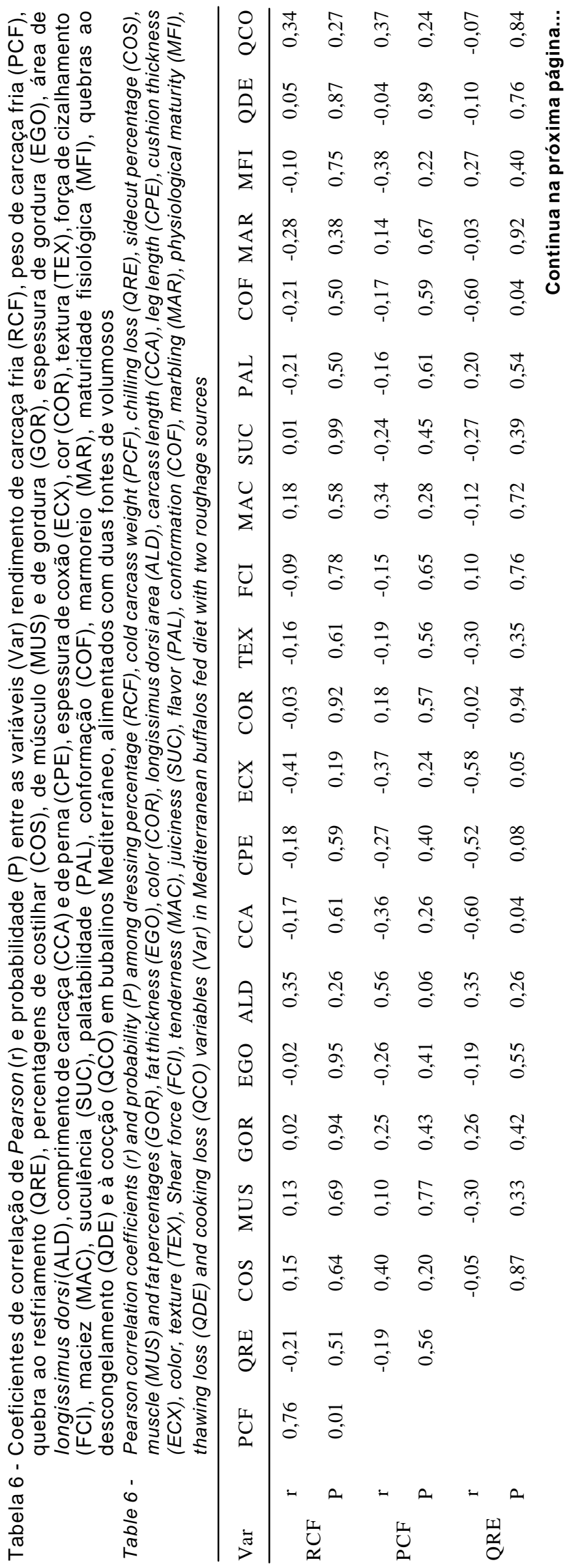




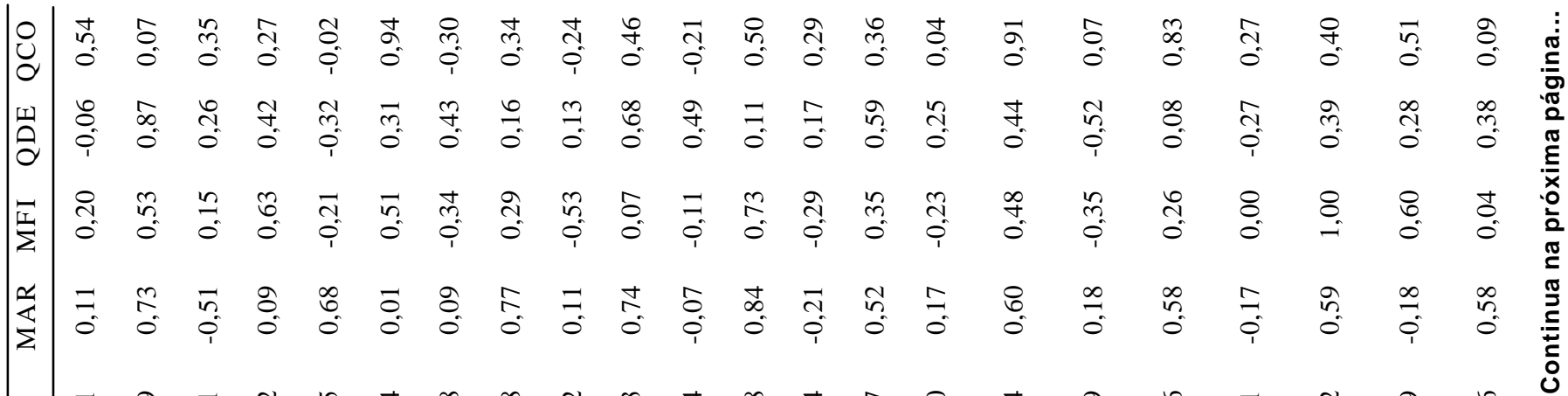

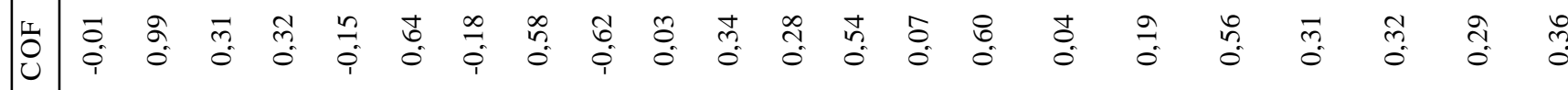

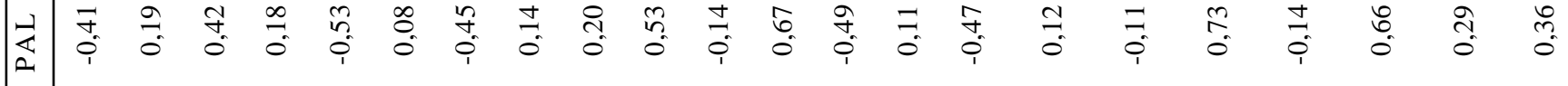

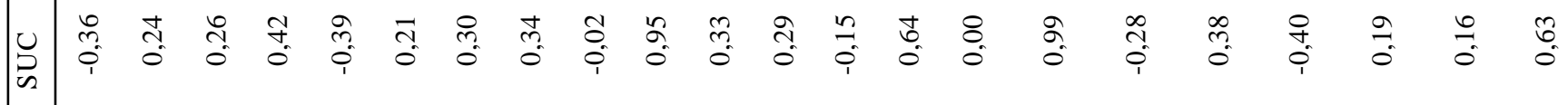

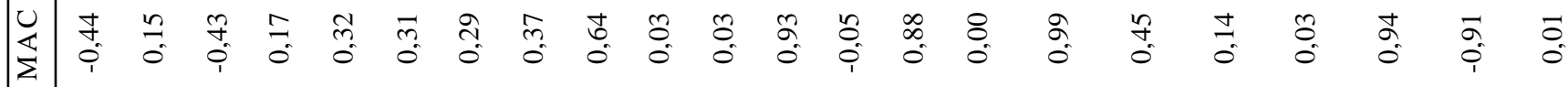

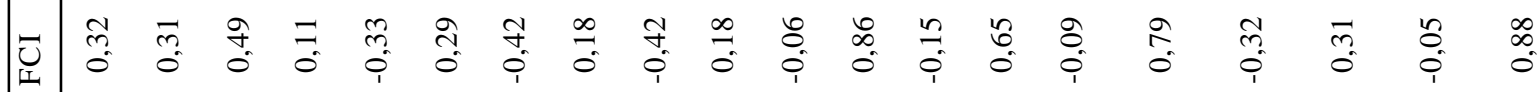

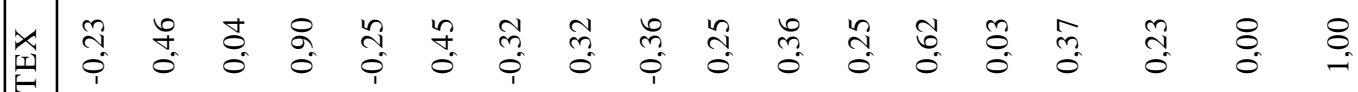

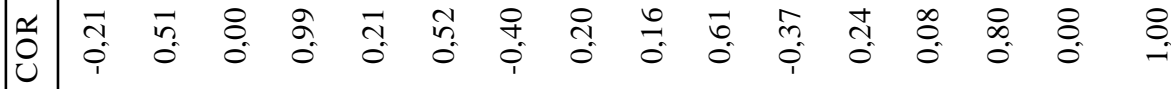

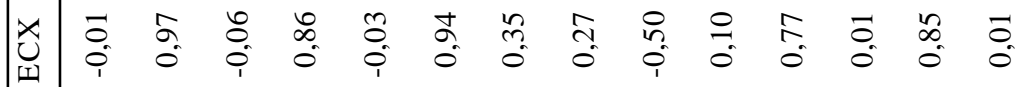

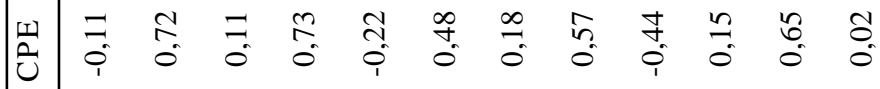

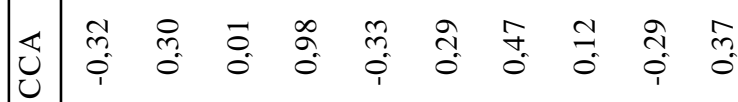

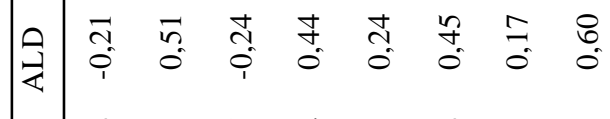

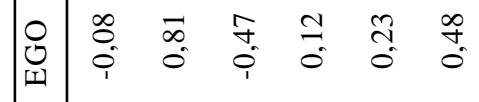

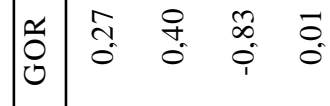

\begin{tabular}{lll}
$n$ & $n$ & $n$ \\
2 & 0 & 0 \\
\hdashline & 0
\end{tabular}

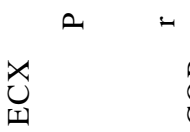




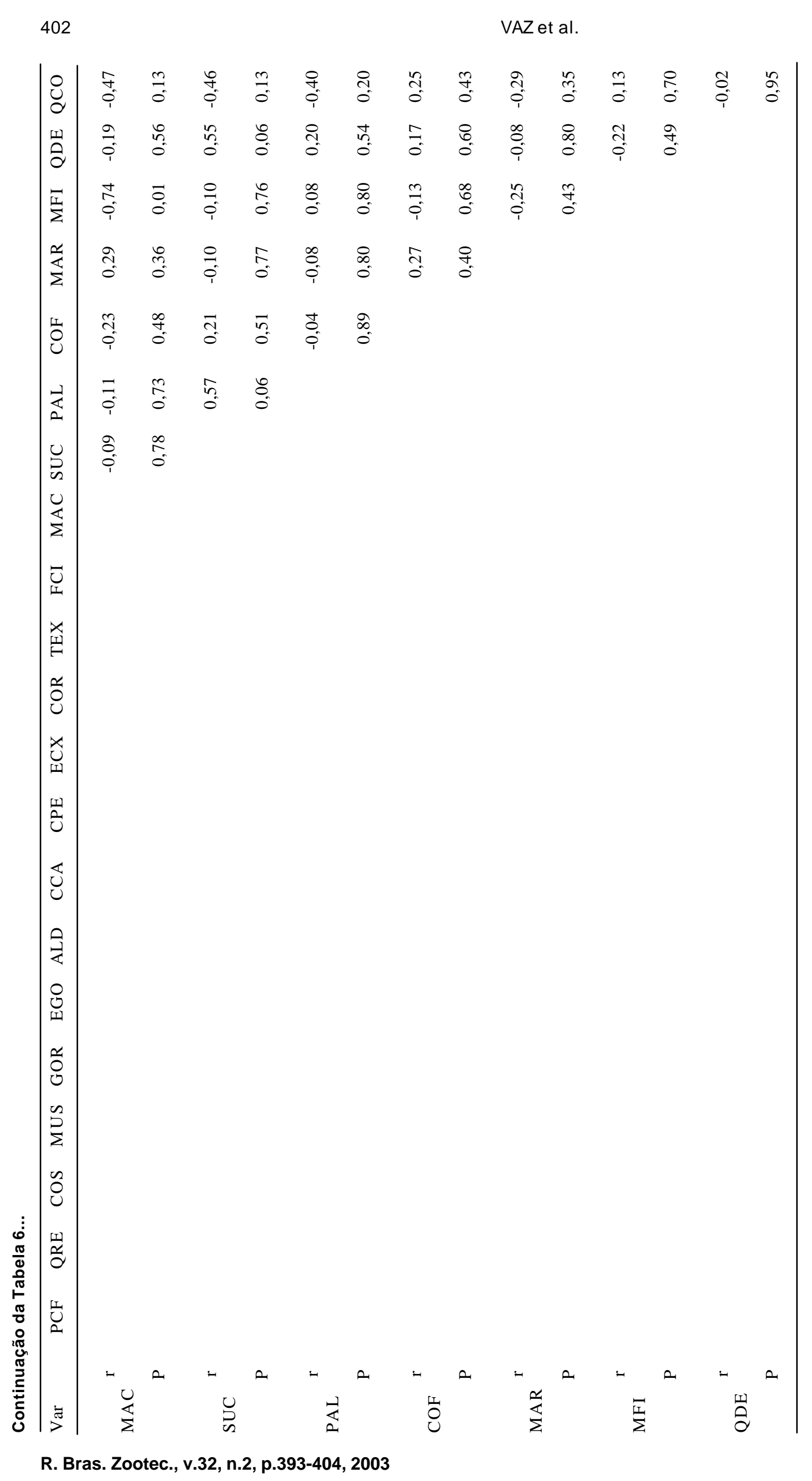


os quais afirmam que, em bovinos, o rendimento de carcaça aumenta com o incremento no peso de abate e na deposição de gordura na carcaça. No presente estudo, os coeficientes de correlação entre rendimento de carcaça com espessura de gordura e porcentagem de gordura estiveram próximos de zero.

Ainda na Tabela 6 , pode-se observar que a quebra ao resfriamento da carcaça esteve negativamente correlacionada $(\mathrm{P}<0,05)$ com o comprimento de carcaça, a espessura de coxão e a conformação, sendo os coeficientes de $-0,60,-0,58$ e $-0,60$, respectivamente, mostrando que carcaças mais compridas e com maior musculosidade apresentaram menores perdas durante o resfriamento. Já a área de longissimus dorsi apresentou correlação significativa com a conformação e a maciez da carne. Vaz (1999) verificou que a correlação entre maciez da carne e área de longissimus dorsi não foi significativa em novilhos Nelore $(r=0,15)$ ou em novilhos Charolês $(r=0,04)$, quando os mesmos foram abatidos aos dois anos de idade.

A maciez da carne e a força de cizalhamento foram significativamente correlacionadas com a maturidade fisiológica, mostrando que animais com maturidade mais avançada apresentaram carne com menores valores de maciez $(\mathrm{r}=-0,74 ; \mathrm{P}<0,01)$ e maiores valores de força de cizalhamento $(r=0,60$; $\mathrm{P}<0,04)$, constatando-se que o incremento no consumo de carne de bubalinos deve ser fomentado com o abate de animais jovens, os quais resultam em carne de melhor qualidade (Preston \& Willis, 1974; Berg \& Butterfield, 1976; Boggs \& Merkel, 1981; Muller, 1987).

\section{Conclusões}

Bubalinos Mediterrâneo terminados em confinamento com silagem de milho apresentaram maior rendimento de carcaça que bubalinos da mesma raça terminados com cana-de-açúcar.

Bubalinos Mediterrâneo terminados em confinamento aos 20 meses apresentaram carne de melhor palatabilidade e suculência, quando recebe ram cana-de-açúcar na dieta em comparação ao fornecimento de silagem de milho.

A correlação é significativa entre a maturidade fisiológica e as características que expressam a maciez da carne. Os resultados também mostraram que as carcaças mais compridas e mais musculosas apresentam menor quebra durante o resfriamento.

\section{Literatura Citada}

BERG, R.T.; BUTTERFIELD, R.M. New concepts of cattle growth. Sydney: Sydney University Press, 1976. 240p.

BRONDANI, I.L.; RESTLE, J. Efeito das dietas contendo canade-açúcar ou silagem de milho no desempenho de novilhos em confinamento. Ciência Rural, v.21, n.1, p.129-134, 1991.

BOGGS, D.L.; MERKEL, R.A. Live animal: Carcass evaluation and selection manual. Iowa: Michigan State University, 1981. 199p.

CHARLES, D.D.; JOHNSON, E.R. Liveweight gains and carcass composition of buffalo (Bubalus bubalis) steers on four feeding regimes. Australian Journal of Agricultural Research, v.26, p.407-413, 1975.

COSTA, L.N.; RODRIGUES, R.R.; MEDEIROS, E.L. et al. Evaluation of feeding systems for buffaloes during winter in southern Brazil. In: WORLD BUFFALO CONGRESS, 4., 1994, São Paulo. Proceedings... São Paulo: Associação Brasileira de Criadores de Búfalos/FAO/FINEP, 1994. v.2, p.64-66.

DI MARCO, O.N. Crecimiento y respuesta animal.Balcarce: Associación Argentina de Producción Animal, 1994. 129p.

FRANZOLIN, R.; SILVA, J.R. Níveis de energia na dieta para bubalinos em crescimento alimentados em confinamento. 2. Características de carcaça. Revista Brasileira de Zootecnia, v.30, n.6, p.1880-1885, 2001.

GIGLI, S.; FAILLA, S.; CARRETTA, A. et al. Growth of young bulls: liveweight, carcass and meat. In: WORLD BUFFALO CONGRESS, 4., 1994, São Paulo, Proceedings. São Paulo: Associação Brasileira de Criadores de Búfalos/FAO/FINEP, 1994. v.2, p.18-20.

HANKINS, O.G.; HOWE, P.E. Estimation of the composition of beef carcasses and cuts. Washington: United States Department of Agriculture (Technical Bulletin, 926), 1946. $20 \mathrm{p}$

JOKSIMOVIC, J. Physical, chemical and structural characteristics of buffalo meat.Arhiv Za Poljoprivredne Nauke, v.22, n.78, p.110-151, 1969.

JORGE, A.M.; FONTES, C.A.A.; FREITAS, J.A. et al. Rendimento da carcaça e de cortes básicos de bovinos e bubalinos, abatidos em diferentes estádios de maturidade. Revista Brasileira de Zootecnia, v.26, n.5, p.1048-1054, 1997.

LORENZONI, W.R.; CAMPOS, J.; GARCIA, J.A. et al. Ganho de peso, eficiência alimentar e qualidade da carcaça de novilhos búfalos, nelores, holandeses e mestiços holandês-zebu. Revista da Sociedade Brasileira de Zootecnia, v. 15, n.6, p.486-497, 1986.

MACEDO, M.P.; BIANCHINI SOBRINHO, E.; RESENDE, F.D. et al. Características de carcaça de bubalinos da raça Mediterrâneo terminados em diferentes regimes alimentares. In: REUNIÃO ANUAL DA SOCIEDADE BRASILEIRA DE ZOOTECNIA, 37., 2000, Viçosa, MG. Anais... Viçosa: Sociedade Brasileira de Zootecnia, 2000. p.355.

MARTINEZ, J.L. Terminação de bubalinos em regime de confinamento recebendo duas dietas com diferentes relações de volumoso e concentrado. In: REUNIÃO ANUAL DA SOCIEDADE BRASILEIRA DE ZOOTECNIA, 37., 2000, Viçosa, MG. Anais... Viçosa: Sociedade Brasileira de Zootecnia, 2000. p.489.

MAZZA, C.A.S.; ANDRADE, V.J.; CANGUSSU, M.A. Estudo comparativo do rendimento de carcaças de bovinos e bubalinos terminados em confinamento. Arquivos Brasileiros de Medicina Veterinária e Zootecnia, v.36,n.6,p.733-741, 1984. 
MOLETTA, J.L.; SILVA, M.E.T.; MARTINEZ, J.L. Desempenho de bubalinos na fase de recria/engorda em pastagem de humidicula e hemarthria no litoral do Paraná. II - Características de carcaça. In: REUNIÃO ANUAL DA SOCIEDADE BRASILEIRA DE ZOOTECNIA, 30., 1993, Rio de Janeiro. Anais... Niterói: Sociedade Brasileira de Zootecnia, 1993a. p.495.

MOLETTA, J.L.; SILVA, M.E.T.; MARTINEZ, J.L. et al. Estudo de características de carcaça de bubalinos. In: REUNIÃO ANUAL DA SOCIEDADE BRASILEIRA DE ZOOTECNIA, 30., 1993, Rio de Janeiro. Anais... Niterói: Sociedade Brasileira de Zootecnia, 1993b. p.259.

MOLETTA, J.L.; RESTLE, J. Características de carcaça de novilhos de diferentes grupos genéticos terminados em confinamento. Revista da Sociedade Brasileira de Zootecnia, v.26, n.5, p.876-888, 1996a.

MOLETTA, J.L.; RESTLE, J. Influência do grupo genético sobre características qualitativas da carne de novilhos. Revista da Sociedade Brasileira de Zootecnia, v.26, n.5, p.866-875, 1996b.

MULLER, L. Normas para avaliação de carcaças e concurso de carcaça de novilhos. 2.ed. Santa Maria: Universidade Federal de Santa Maria, 1987. 31p.

MULLER, L.; AGUIRRE, L.F.; RESTLE, J. et al. Carcass and meat quality of cattle and buffalo (Bubalus bubalis). In: INTERNATIONAL CONGRESS OF MEAT SCIENCE AND TECHNOLOGY, 37., 1991, Kulmbach, Germany. Proceedings... Kulmbach: FAO, 1991. v.1, p.165-169.

MULLER, L.; AGUIRRE, L.F.; FEIJÓ, G.L.D. et al. Buffalo meat quality when submitted to three feeding regimens. In: WORLD BUFFALO CONGRESS, 4., 1994, São Paulo, Proceedings... São Paulo: Associação Brasileira de Criadores de Búfalos/FAO/FINEP, 1994a. v.2, p.107-109.

MULLER, L.; AGUIRRE, L.F.; FEIJÓ, G.L.D. et al. Performance of buffaloes when submitted to three grazing regimens during winter. In: WORLD BUFFALO CONGRESS, 4., 1994, São Paulo. Proceedings... São Paulo: Associação Brasileira de Criadores de Búfalos/FAO/FINEP, 1994b. v.2, p.107-109.

PRESTON, T.R.; WILLIS, M.B. Intensive beef production, 2.ed. Oxford: Pergamon Press, 1974. 546p.

RESTLE, J.; SOUZA, E.V.T.; NUCCI, E.P.D. et al. Performance of cattle and buffalo fed with different sources of roughage. In: WORLD BUFFALO CONGRESS, 4., 1994, São Paulo. Proceedings... São Paulo: Associação Brasileira de Criadores de Búfalos/FAO/FINEP, 1994. v.2, p.301-303.

RESTLE, J.; VAZ, F.N.; SILVA, N.L.Q. et al. Aspectos qualitativos da carcaça e da carne de novilhos, terminados aos 24 meses, com diferentes silagens de sorgo. In: REUNIÃO ANUAL DA SOCIEDADE BRASILEIRA DEZOOTECNIA, 35., 1998, Botucatu.Anais... Botucatu: Sociedade Brasileira de Zootecnia, 1998. p.143-145.
RESTLE, J.Confinamento, pastagens e suplementação para produção de bovinos de corte. Santa Maria: Universidade Federal de Santa Maria, 1999. 258p.

RESTLE, J.; VAZ, F.N. Confinamento de bovinos puros e cruzados. In: LOBATO, J.F.P.; BARCELLOS, J.O.J.; KESSLER, A.M. (Eds.) Produção de bovinos de corte, Porto Alegre: EDIPUCRS, 1999. p.141-168.

ROBERTSON, J.; RATCLIFF, D.; BOUTON, P.E. et al. A comparison of some properties of meat from young buffalo (Bubalus bubalis) and cattle. Journal of Food Science, v.51, n.1, p.47-50, 1986.

RODRIGUES, V.C.; ANDRADE, I.F.; SOUSA, A.I.N. et al. Desempenho de bubalinos e bovinos em confinamento. In: REUNIÃO ANUAL DA SOCIEDADE BRASILEIRA DE ZOOTECNIA, 37., 2000, Viçosa, MG. Anais... Viçosa, MG: Sociedade Brasileira de Zootecnia, 2000. p.385.

SAS INSTITUTE. SAS language reference. Version 6, Cary: 1990. 1042p.

VAZ, F.N.; RESTLE, J. Produção de carne com qualidade. In: RESTLE, J.; BRONDANI, I.L.; PASCOAL, L.L. et al. (Eds.) Produção intensiva com qualidade em bovinos de corte, Santa Maria: Universidade Federal de Santa Maria, 1998. p.104-119.

VAZ, F.N. Cruzamento alternado das raças Charolês e Nelore: características de carcaça e da carne de novilhos abatidos aos dois anos. Santa Maria: Universidade Federal de Santa Maria, 1999. 58p. Dissertação (Mestrado em Zootecnia) - Universidade Federal de Santa Maria, 1999.

VAZ, F.N.; VAZ, R.Z.; ROSO, C. Tipos e níveis de concentrado para confinamento. In: RESTLE, J. (Ed.) Eficiência na produção de bovinos de corte. Santa Maria: Universidade Federal de Santa Maria, 2000. p.219-257.

VAZ, F.N.; RESTLE, J.; ALVES FILHO, D.C. et al. Peso das vísceras e rendimento de carcaças de novilhos ou novilhas Braford superprecoces, terminados com suplementação em pastagem cultivada sob pastejo controlado. In: REUNIÃO ANUAL DA SOCIEDADE BRASILEIRA DE ZOOTECNIA, 38., 2001, Piracicaba. Anais...Viçosa, MG: Sociedade Brasileira de Zootecnia, 2001. p.1531-1532. 